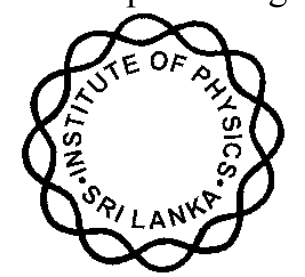

INSTITUTE OF PHYSICS - SRI LANKA

Research Article

\title{
Conducting Polymer /Graphene composite electrodes for supercapacitors
}

\author{
D.S.K. Rajaguru, K.P. Vidanapathirana*, K.S. Perera \\ Polymer Electronics Research Group, Department of Electronics, Wayamba University of \\ Sri Lanka, Kuliyapitiya, Sri Lanka
}

\begin{abstract}
Graphene, as a new emerging carbonaceous material has gained a lot of attention in the past decade due to its extraordinary intrinsic properties. Conducting polymers exhibit high potential in supercapacitors because of their advantages over other electrode materials including good conductivity, flexibility, ease of synthesis etc. But both materials have some drawbacks when they merely used as electrodes. Therefore, research community has move towards composite electrodes to avoid disadvantageous realities and accomplish the best performance. This review summarizes recent development of graphene and conducting polymer (Polypyrrole and Polyaniline) based composite electrodes for supercapacitors and the comparison of their performance.
\end{abstract}

Keywords: Conducting polymer, Graphene, Supercapacitor, Composite electrode, Specific capacitance

*Corresponding author: kamalpv@wyb.ac.lk

https://orcid.org/0000-0003-0676-7627 


\section{INTRODUCTION}

From the past over several decades, due to industrialization, increase in global population, rapid development of the global economy, depletion of fossil fuels, and increasing environmental pollution, there is an urgent need for efficient, clean and sustainable sources of energy, as well as new technologies associated with energy conversion and storage devices, such as batteries, fuel cells and supercapacitors ${ }^{1}$. Due to its high power density over batteries fuel cells (which have high energy storage), high energy density compared to the conventional capacitors (which have high power output), and long lifecycle, supercapacitors or ultracapacitors become prominent. For these supercapacitors to realize their promise in the outcome, it is important that their energy and power densities must be maximized ${ }^{2}$. To increase the performance of supercapacitors, different materials and various methods were used in recent years. However, the performance of supercapacitors depends mainly on the electrode material and the properties of the electrode/electrolyte interface. Therefore, it is important that the electrode materials should demonstrate high capacitance, good mechanical and structural stability to reach long cycling life ${ }^{3}$. At present, the electrode materials of supercapacitors can be mainly divided into two categories. One is carbon-based materials with electric double-layer feature including graphene, carbon nanotubes, porous carbon, carbon foam, activated carbon, carbon fiber and so on ${ }^{4}$. Second electrode material type is mainly conducting polymers (e.g., polyaniline, polypyrrole) and/or metal oxides which has pseudocapacitive feature through redox reactions to achieve the electron transfer and charge storage ${ }^{3}$. These standard supercapacitors have two identical electrodes which aligned symmetrically and the charges are stored electrostatically in electric double layer capacitors (EDLCs) and faradaically in pseudocapacitors or redox capacitors at the electrochemical double layer situated in the electrode/ electrolyte interfaces ${ }^{5}$. EDLCs utilize the high surface area of carbonaceous materials and exhibit a high power density and excellent cycle life. However, they have lower energy density due to the low areal capacitance of electrode materials and narrow operating potentials ${ }^{4}$. Redox capacitors are also suffering from some drawbacks, such as lower energy and power densities and poor cycling stabilities. Therefore, to avoid these weaknesses and improve performances recent research works have moved towards to merge the electrodes of EDLCs and redox capacitors. However, supercapacitors can be much more complex devices when combined different materials for electrode fabrication. These hybrid capacitors try to develop the relative advantages and diminish the relative disadvantages of EDLCs and redox capacitors to comprehend better performances by utilizing both faradaic and electrostatic processes to store charge and have achieved 
energy and power densities greater than EDLCs. EDLCs consist of carbon-based materials which have large surface area, high porosity, controllable morphology and high electrical conductivity. Moreover, these carbon materials can be treated to modify its structural properties and thereby to accumulate chemical and physical properties for numerous applications ${ }^{6}$. Scientists believed that the increasing specific surface area will increase the capacitance of EDLCs ${ }^{7}$. Therefore, from its discovery in 2004, graphene with one atom thickness and large specific area has attracted the major focus of supercapacitor industry ${ }^{8}$. Thermal conductivity and mechanical stiffness of these graphene sheets (one-atom-thick two-dimensional layers of $\mathrm{sp}^{2}$-bonded carbon) may rival the remarkable in-plane values for graphite (3,000 $\mathrm{W} \mathrm{m}^{-1} \mathrm{~K}^{-1}$ and 1,060 GPa, respectively); and recent studies have shown that individual graphene sheets have extraordinary electronic transport properties which got the attention for energy storage applications ${ }^{9}$. Two-dimensional (2D) graphene has exhibited unusual and intriguing physical, chemical and mechanical properties due to its honeycomb lattice structure. The use of graphene has overtaken the use of carbon nanotubes (CNTs) because CNTs restricted from achieving electric double-layered capacitance for industrial devices ${ }^{10}$. Today, most research works on graphene-based supercapacitors concentrate on using graphene nano-platelets, graphene nano-powders and other graphene derivatives such as graphene oxide, reduced graphene oxide, chemical modified graphene, etc. Even though the highest quality and least defects in graphene sheet were obtained via chemical vapor deposition (CVD) which cannot compete against activated carbon due to its high manufacturing cost and hard scalability ${ }^{8,11}$. To obtain better contact in the current collector, polymer binders, specifically, fluoropolymers like polyvinylidene fluoride (PVDF) and polytetrafluoroethylene (PTFE) were used. The low conductivity of these polymer binders could lead to a decrease in energy density in supercapacitors. Therefore, rather than using only a binder, scientists have tested conducting polymer (CP) to comprehend both factors. These conducting polymers are electrically conductive and can undergo redox reactions to fulfill pseudo-capacitance in addition to the electric double layer capacitance ${ }^{8}$. Polypyrrole (PPy), polyaniline (PANI), and Poly(3,4-ethylenedioxythiophene) (PEDOT) are the three most commonly used CPs in supercapacitors due to their excellent conductivity, high capacitance, ease of synthesis, low cost, good flexibility and lightweight ${ }^{12}$. However, it is a challenge to build high power supercapacitors using CPs because they exhibit poor stabilities during the charge-discharge processes ${ }^{10}$. In recent times, activated carbon and CNTs have been used to fabricate supercapacitors due to their good stability, but these microstructures limit the value of the capacitance. Therefore CNT-PANI has been tested in supercapacitor 
electrodes to improve the capacitance. While doing so the PANI stability increased as well 13. In this review we mainly focused on the recent supercapacitor electrodes fabricated from composite materials such as graphene-polyaniline (G-PANI) and graphene-polypyrrole (GPPy), for energy applications. Thereby, the review allows to comprehending the technology of using graphene and conducting polymer composite electrodes in supercapacitor industry and mitigates the disadvantages of using sole graphene electrodes or conducting polymer electrodes.

\section{GRAPHENE BASED ELECTRODES FOR SUPERCAPACITORS}

One atom thick, 2D layer graphene is a unique carbon material that has potential for energy storage device applications ${ }^{14}$. Recently, it was proposed that graphene can be used as a material for supercapacitor applications due to its outstanding characteristics like high electrical conductivity, chemical stability, large surface area and mainly because it doesn't depend on the distribution of pores at solid state, when compared with other carbon materials such as activated carbon, CNT etc. ${ }^{15}$. Among all carbon materials used as electrochemical double layer capacitor electrodes, newly developed graphene has the highest specific surface area (SSA) which can be larger than $2630 \mathrm{~m}^{2} \mathrm{~g}^{-1}{ }^{16}$. This graphene is capable of achieving an ultra-high specific capacitance if the entire SSA is fully utilized ${ }^{14}$. According to Xia et al. single-layer graphene has the theoretical specific capacitance of $\sim 21 \mathrm{uF} \mathrm{cm}^{-2}$ and the corresponding specific capacitance is $\sim 550 \mathrm{~F} \mathrm{~g}^{-1}$ when the entire surface area is fully utilized 17. However, in the practical situation due to serious agglomeration during both preparation and application processes, expected values were not observed ${ }^{18}$. Therefore, different graphene synthesis methods and various electrode preparation processes were considered to obtain the maximum capacitance values. Nowadays, there are many different approaches being tested for the production of graphene varieties such as CVD, micromechanical exfoliation, arch discharge method, unzipping of CNTs, epitaxial growth, electrochemical and chemical methods and intercalation methods in graphite ${ }^{19}$. Another major advantage of using graphene as electrode material is that the both major surfaces of graphene sheet are exterior and therefore can be readily accessible by electrolyte material ${ }^{20}$. Even though mechanical exfoliation of graphite using scotch tape method gives high quality graphene, this method is not suitable for mass production ${ }^{19}$. Mitra et al. observed specific capacitances from 0.74 to $0.98 \mathrm{mF} \mathrm{cm}^{-2}$ for supercapacitor using exfoliated graphite electrodes with a solid electrolyte of polyethylene oxide-ethylene carbonate-propylene carbonate- $\mathrm{LiClO}_{4}$, together with a long cycle life and a short response time in the order of milliseconds ${ }^{21}$. Lv 
et al. found a novel approach to obtain low temperature exfoliated graphene which exhibits good energy storage performance when compared with high temperature exfoliated graphene ${ }^{22}$. Graphene undergo agglomeration which leans towards to restack back to graphite. To reduce this issue several methods are being examined. As a result, Fan et al. developed highly corrugated graphene sheets using thermal reduction of graphite oxide at a high temperature followed by a rapid cooling in liquid nitrogen which gives high specific capacitance of $349 \mathrm{~F} \mathrm{~g}^{-1}$ in $6 \mathrm{M} \mathrm{KOH}$ aqueous solution ${ }^{23}$. Graphene oxide (GO) same as graphite oxide is another significant graphene derivative, which can readily made by graphite. Due to the disruption of its $\mathrm{sp}^{2}$ bonding networks, GO is often described as an electrical insulator. But in reality, this could vary due to incomplete oxidization ${ }^{24}$. These GOs can be synthesized using modified Hummers method from powdered flake graphite ${ }^{25}$. Depending on the GO synthesis techniques, different functional groups and their various distributions on the surface can be seen. Stankovich et al. suggested an alternative method for creating single sheets starting from GO exfoliation to create stable aqueous dispersions of individual sheets ${ }^{26}$. Insulating GO can be converted into graphene by a controllable reduction of GO along with the reducing agent hydrazine hydrate which is an efficient and a low cost method. Reduction of GO is the removal of oxygen containing functional groups in GO such as hydroxyl, carboxyl and epoxy groups giving reduced GO (rGO) ${ }^{16}$. Ruoff et $a l$. introduced the chemically modified graphene (CMG) as electrode materials to obtain the specific capacitances of 135 and $99 \mathrm{~F} \mathrm{~g}^{-1}$ in aqueous and organic electrolytes, respectively. These CMG materials are made from 1-atom thick sheets of carbon and functionalized as required ${ }^{27}$. Li et al. prepared graphene nanosheets by chemical modification with $\mathrm{KOH}$. The specific capacitance was checked using cyclic voltammetry and the value reach up to about $136 \mathrm{~F} \mathrm{~g}^{-1}$, which is an increase of $35 \%$ with that of pristine graphene nanosheets ${ }^{28}$. Table 01 summarizes the electrochemical performances of electrodes based on graphene and its derivatives.

Table 01: Electrochemical performances of different graphene electrodes.

\begin{tabular}{|c|c|c|c|}
\hline Electrode & Electrolyte & Specific capacitance & Reference \\
\hline Carbon Dots/ rGO & $1 \mathrm{M} \mathrm{H}_{2} \mathrm{SO}_{4}$ & $211.9 \mathrm{~F} \mathrm{~g}^{-1}\left(\right.$ at $\left.0.5 \mathrm{~A} \mathrm{~g}^{-1}\right)$ & 29 \\
\hline $\mathrm{GO}$ & $0.01 \mathrm{M} \mathrm{Fe}(\mathrm{CN})_{6}$ & $223.6 \mathrm{~F} \mathrm{~g}^{-1}\left(\right.$ at $\left.5 \mathrm{~m} \mathrm{~V} \mathrm{~s}^{-1}\right)$ & 30 \\
\hline $\mathrm{GO}$ & $1 \mathrm{M} \mathrm{H}_{2} \mathrm{SO}_{4}$ & $265.0 \mathrm{~F} \mathrm{~g}^{-1}\left(\right.$ at $\left.1 \mathrm{~A} \mathrm{~g}^{-1}\right)$ & 31 \\
\hline
\end{tabular}




\begin{tabular}{|c|c|c|c|}
\hline Graphene & $\begin{array}{c}\mathrm{H}_{2} \mathrm{SO}_{4} \text {-polyvinyl alcohol } \\
\text { (PVA) }\end{array}$ & $\begin{array}{c}\text { Areal } 80.7 \mu \mathrm{F} \mathrm{cm}^{-2} \\
\text { Stack } 17.9 \mathrm{~F} \mathrm{~cm}^{-3}\end{array}$ & 32 \\
\hline Graphene & $\begin{array}{c}70 \% \text { of } 1.4 \mathrm{M} \mathrm{Li}_{2} \mathrm{SO}_{4}+30 \% \\
\text { of ethylene glycol }\end{array}$ & $99.0 \mathrm{~F} \mathrm{~g}^{-1}$ & 33 \\
\hline
\end{tabular}

\section{CONDUCTING POLYMER BASED ELECTRODES FOR SUPERCAPACITORS}

Conducting polymers (CPs) are realized as promising materials for the high-performance supercapacitors. They have high specific capacitances because of their charge processes concern the whole polymer mass not only limits to the surface as in the case of carbon-based materials. Moreover, they exhibit high conductivities in the charged states, while their charge-discharge processes are generally fast. This review will focus on the use of two conducting polymers, polyaniline (PANI), polypyrrole (PPy) composites with graphene as supercapacitor electrodes.

\subsection{PANI}

PANI has been studied and experimented in a wide range as an electrode material for supercapacitors due to its high conductivity, electroactivity, specific capacitance, good stability in air and ease of synthesis ${ }^{8}$. PANI to be used as supercapacitor electrode material, a protic solvent (acidic medium/ protic ionic liquid) is required ${ }^{34}$. PANI can be synthesized by various techniques, and by these different methods, properties of PANI will vary. Most common two synthesis methods are oxidative polymerization and electrochemical polymerization. In addition to that, interfacial polymerization, electrospinning, seeding polymerization and templated polymerization also play a major role in PANI preparation 35-38. Even though, theoretically, PANI can reach up to specific capacitance value of $2000 \mathrm{~F}$ $\mathrm{g}^{-1}$, experimental values are much lower. According to $\mathrm{Q}$. Meng et al. this is due to the amount of PANI contribution to capacity is being smaller and the effective PANI percentage is depended on the both PANI conductivity and diffusion of counter-anions ${ }^{39}$. Sivakkumar et al. synthesized PANI nanofibers by interfacial polymerization and the fabricated redox supercapacitor composed as a two-electrode cell giving initial specific capacitance of $554 \mathrm{~F}$ $\mathrm{g}^{-1}$ at $1.0 \mathrm{~A} \mathrm{~g}^{-1}$ but decreases rapidly upon continuous cycling ${ }^{40}$. Peng et al. was able to prepared PANI powder by chemical solution polymerization, and the electrochemical properties of PANI single electrode with $1 \mathrm{M} \mathrm{HCl}$ and $1 \mathrm{M} \mathrm{H}_{2} \mathrm{SO}_{4}$ electrolyte solutions were tested using galvanostatic charge-discharge (GCD) and cyclic voltammetry $(\mathrm{CV})$ tests and 
have been found specific capacitance of $302.43 \mathrm{~F} \mathrm{~g}^{-1}{ }^{41}$. PANI applied in supercapacitors in pure form has been studied a lot where its specific capacitance value reaches up to several hundreds in experimental level. But PANI's some electrochemical performances, especially cycling ability still unable to reach practical application requirements in daily life. Specific capacitance of PANI being much relied on the synthesis conditions and only applicable to proton type electrolytes are disadvantageous facts to PANI in supercapacitor electrodes. Hence, scientists try to overview different approaches while researching for the preparation of PANI based composites (with carbon materials and/or metal oxides) to overcome the challenging situation which will be discuss later on in this review.

\subsection{PPy}

PPy, as one of the major conducting polymer, has become a promising electrode material for supercapacitors due to its intrinsic properties such as high electrical conductivity and interesting redox reactivity. Flexibility, ease of fabrication, relatively high specific capacitance per unit volume, high cycling stability, applicable to neutral electrolytes are some of the main advantages of $\mathrm{PPy}{ }^{39}$. Yang et al. obtained maximum specific capacitance of $261 \mathrm{~F} \mathrm{~g} \mathrm{~g}^{-1}$ at $25 \mathrm{mV} \mathrm{s}^{-1}$ for PPy films which synthesized via oil/water interfacial polymerization ${ }^{42}$. Similarly, nanostructured conductive PPy hydrogel was synthesized by interfacial polymerization to reach specific capacitance value of $380 \mathrm{~F} \mathrm{~g}^{-1}$ which showed good mechanical properties and excellent rate capability ${ }^{43}$. Hashmi et al. observed capacitance values to be in the range of $15.3-22.5 \mathrm{mF} \mathrm{cm}{ }^{-2}$ which is equivalent to single electrode specific capacitance of $120-178 \mathrm{~F} \mathrm{~g}^{-1}$ of PPy that corresponding to the energy density values of 16.7-24.7 $\mathrm{Wh} \mathrm{kg}^{-1}$ and power densities $1.6-2.8 \mathrm{~kW} \mathrm{~kg}^{-1}$ in the working voltage $1.0 \mathrm{~V}$ for PPy redox capacitors ${ }^{44}$. Zhi et al. fabricated solid-state supercapacitor which possess a specific capacitance value of $170 \mathrm{~F} \mathrm{~g}^{-1}$ at $0.5 \mathrm{~A} \mathrm{~g}^{-1}$ and showed that the performance can be effectively enhance up to $214 \mathrm{~F} \mathrm{~g} \mathrm{~g}^{-1}$ with a $20 \%$ strain ${ }^{45}$. Li et al. was able to prepare PPy flexible film via chemical oxidation technique which exhibited specific capacitance of $576 \mathrm{~F} \mathrm{~g}^{-1}$ at $0.2 \mathrm{~A} \mathrm{~g}^{-1}$ with the $1 \mathrm{M} \mathrm{KCl}$ electrolyte ${ }^{46}$. Rajesh et al. prepared a thin film of PPy doped with phytic acid that can act as a supercapacitor electrode to give specific capacitance of $343 \mathrm{~F} \mathrm{~g}^{-1}$ at the scan rate of $5 \mathrm{mV} \mathrm{s}^{-1} 47$. Even though there is a need for an improvement of cycling stability $\mathrm{Xu}$ et al. was able to prepare conductive cotton fabrics coated with PPy via an in-situ polymerization method which can directly use as a supercapacitor electrode exhibiting specific capacitance of $325 \mathrm{~F} \mathrm{~g}^{-1}$ and energy density of 24.7 $\mathrm{Wh} \mathrm{kg}^{-1}$ at current density of $0.6 \mathrm{~mA} \mathrm{~cm}{ }^{-2} 48$. PPy based electrode properties are mainly lying upon many factors; synthesis method, substrate, dopant, template as well as the 
electrolyte which it tested with. Also, specific capacitance (per unit gram) is relatively low compared to that of PANI ${ }^{39}$. Hence, by optimizing all these crucial factors great improvement for the electrochemical properties of PPy can be achieved. To obtain a greater performance in practical applications, further works on PPy composites may provide a huge benefit.

\section{CONDUCTING POLYMER/GRAPHENE COMPOSITES}

Although pure conducting polymers (PANI, PPy) possess a lot of unique properties, they might not appropriate as electrodes active materials alone in the supercapacitor due to the drawbacks mentioned earlier. In order to improve the electrochemical performances of CPbased supercapacitors, researchers have tried to synthesize binary and even ternary composites with other active materials, mainly including carbon materials (which in this case: graphene-based materials) will be reviewed hereinafter.

\subsection{Graphene-Polyaniline (G-PANI) composites}

Various G-PANI nanocomposites have been studied, such as PANI and nitrogen-dopedgraphene (NG), PANI/nitrogen doped GO or rGO, PANI/graphene hydrogel (GH) ${ }^{10,49-54}$. Khosrozadeh et al. were able to fabricate an electrode composing with PANI, graphene and silver nanowires which gave a specific capacitance of $73.4 \mathrm{~F} \mathrm{~g} \mathrm{~g}^{-1}$ at a discharge rate of $1.1 \mathrm{~A}$ $\mathrm{g}^{-1}$, power density of $468.8 \mathrm{~W} \mathrm{~kg}^{-1}$ and energy density of $5.1 \mathrm{Wh} \mathrm{kg}^{-155}$. Zang et al. fabricated a PANI/NG composite through in-situ polymerization method while having GO in the acid, which have given a specific capacitance value of $480 \mathrm{~F} \mathrm{~g}^{-1}$ at current density of $0.1 \mathrm{~A} \mathrm{~g}^{-1}$ and stated that high capacitances and good cycling stability can be obtained by doping bulky PANI with $\mathrm{GO} / \mathrm{NG}^{49}$. Gomez at el. synthesized PANI/NG composite via chemical precipitation method to obtain a specific capacitance in the range of $300-500 \mathrm{~F} \mathrm{~g}^{-1}$ at current density of $0.1 \mathrm{~A} \mathrm{~g} \mathrm{~g}^{-1}{ }^{10}$. Cong et al. arranged a flexible PANI/NG nanocomposite by electropolymerizing PANI nanorods on the NG paper which was prepared beforehand, thus giving an excellent specific capacitance of $763 \mathrm{~F} \mathrm{~g}^{-1}{ }^{51}$. Wang et al. prepared a 3D PANI/reduced NG (rNG) by a chemical routine and the fabricated electrode could achieve a maximum specific capacitance of $740 \mathrm{~F} \mathrm{~g}^{-1}$ when the current density is $0.5 \mathrm{~A} \mathrm{~g}^{-1}$ and the retention of initial value remains at $87 \%$ even after performing 1000 constant chargedischarge cycles at $10 \mathrm{~A} \mathrm{~g}^{-1}{ }^{50}$. Sun et al. was able to assemble a self-standing 3D PANI/rGO foam through a template-directed in-situ polymerization method to obtain a specific capacitance of $701 \mathrm{~F} \mathrm{~g}^{-1}$ at current density $1 \mathrm{~A} \mathrm{~g}^{-1}$, whereas the retention maintained to be $92 \%$ of the initial value after 1000 cycles ${ }^{52}$. In addition to that, Du et al. was able to 
synthesized PANI/NG and studied their conductivity properties at different conditions ${ }^{56,57}$. Moreover, Wang et al. prepared fibrillar PANI doped with GO through a soft chemical process, which have given a high conductivity value of $10 \mathrm{~S} \mathrm{~cm}^{-1}$ at $22{ }^{0} \mathrm{C}$ and specific capacitance of $531 \mathrm{~F} \mathrm{~g}^{-1}$ in the potential window $0-0.45 \mathrm{~V}$ when the current density is $0.2 \mathrm{~A}$ $\mathrm{g}^{-1}$ 53. Das et al. synthesized $\mathrm{PANI} / \mathrm{MoO}_{3} / \mathrm{NG}$ nanoplates, ternary composite via an inexpensive and novel approach of in-situ polymerization of aniline. The prepared composite was able to achieve specific capacitance of $734 \mathrm{~F} \mathrm{~g}^{-1}$ at $10 \mathrm{mV} \mathrm{s}^{-1}$ scan rate and the retention of capacity from the initial value was remained at $92.4 \%$ after 1000 cycles at the current density of $\mathrm{A} \mathrm{g}^{-1} 58$. Dhibar et al. prepared a nanocomposite which contained $\mathrm{Ag}$ nanoparticles that decorated on $\mathrm{PANI} / \mathrm{NG}$ through an in-situ polymerization method, exhibiting supercapacitance of $591 \mathrm{~F} \mathrm{~g}^{-1}$ at a scan rate of $5 \mathrm{mV} \mathrm{s}^{-1} 59$. Shayeh et al. synthesized $\mathrm{PANI} / \mathrm{rGO} / \mathrm{Au}$ nanocomposite on glassy carbon which showed higher specific capacitance ${ }^{60}$. Kazemi et al. fabricated an asymmetric supercapacitor based on ternary nanocomposite of manganese dioxide-reduced graphene oxide quantum dot-polyaniline (MGP) which demonstrated a high specific capacitance of $423 \mathrm{~F} \mathrm{~g} \mathrm{~g}^{-1}$ at a current density of $5.7 \mathrm{~A} \mathrm{~g} \mathrm{~g}^{-1}$. Capacitance retention was almost $85 \%$ of the initial capacitance value after 2000 chargedischarge cycles ${ }^{61}$. According to Tayel et al. PANI can be integrated with conducting carbon materials for the greater improvement of stability, electrical conductivity and redox behavior to prepared G-PANI composite which has high porosity and large surface area. The fabricated supercapacitor exhibited specific capacitance of $916 \mathrm{~F} \mathrm{~g}^{-1}$ and energy density of 127.2 $\mathrm{Wh} \mathrm{kg}^{-1}{ }^{62}$. Liu et al. obtained a high specific capacitance value of $731.2 \mathrm{~F} \mathrm{~g}^{-1}$ at $5 \mathrm{mV}$ $\mathrm{s}^{-1}$ for GO wrapped PANI hollow microsphere which was prepared using facile selfassembly method. Though it has higher capacitance value, while having other qualities like low density, high specific surface area and good permeation, electrical conductivity and excellent electrochemical property its uses have been limited due to relatively poor cycling life ${ }^{63}$. Kumar et al. prepared a composite electrode with PANI grafted rGO which has fibrillar morphology through electron microscopy, demonstrated electrical conductivity of $8.7 \mathrm{~S} \mathrm{~cm}^{-1}$ at room temperature and specific capacitance of $250 \mathrm{~F} \mathrm{~g}^{-1}{ }^{64}$. Zhang et al. constructed an electrode using highly conductive GH combined with PANI which exhibited excellent electrochemical properties. It showed specific capacitance value of $710 \mathrm{~F} \mathrm{~g}^{-1}$ at 2 $\mathrm{A} \mathrm{g}^{-1}$ and $73 \%$ capacitance retention upon increasing current to $100 \mathrm{~A} \mathrm{~g}^{-1}$. In addition to that, $\mathrm{GH} / \mathrm{PANI}$ electrode gave a maximum energy density of $24 \mathrm{Wh} \mathrm{kg}^{-1}$ and power density of 30 $\mathrm{kW} \mathrm{kg}^{-1}$, and also exhibits $86 \%$ capacitance retention after 1000 cycles ${ }^{54}$. In summary, there 
are various practices to synthesize G-PANI composites which have better electrochemical performances, thus moving towards to comprehend practical application requirements.

\subsection{Graphene-Polypyrrole (G-PPy) composites}

Novel approaches have been made to develop the nanostructured conductive polymer, polypyrrole (PPy) with electrically conductive graphene and its derivatives to achieve higher specific capacitances and good cycling stability. Drzal et al. created $100 \%$ binder free composite electrode with multilayered graphene sheets and PPy nanowires which could reach to specific capacitance of $165 \mathrm{~F} \mathrm{~g} \mathrm{~g}^{-1}$ upon increasing scan rate. Further its cyclic voltammograms showed nearly ideal rectangular shape when rising of the scanning rate implying high electrochemical cyclic stability ${ }^{65}$. Liu et al. performed in-situ intercalative chemical polymerization to obtain hierarchical plush PPy layers intercalated into graphene sheets and prepared G-PPy based supercapacitor which exhibited specific capacitance value of $650 \mathrm{~F} \mathrm{~g}^{-1}$, energy density of $54 \mathrm{Wh} \mathrm{kg}^{-1}$, power density of $778.1 \mathrm{~W} \mathrm{~kg}^{-1}$ and electrical conductivity of $1980 \mathrm{~S} \mathrm{~cm}^{-1} 66$. Xu et al. synthesized G-PPy composite via in-situ chemical oxidation method and the specific capacitance obtained was $318.6 \mathrm{~F} \mathrm{~g}^{-1}$ at a scan rate of 2 $\mathrm{mV} \mathrm{s}^{-1}$. The value decreased to $132.9 \mathrm{~F} \mathrm{~g}^{-1}$ after 1000 cycles at $100 \mathrm{mV} \mathrm{s}^{-1}{ }^{67}$. Basnayake et al. was able to prepared G-PPy by a chemical oxidative polymerization method with a high yield of 97\% which was higher than that of PPy yield of 85\%. This composite exhibited 112 $\mathrm{F} \mathrm{g}^{-1}$ specific capacitance at knee frequency of $125 \mathrm{~Hz}$ and $270 \mathrm{~F} \mathrm{~g}^{-1}$ at $0.1 \mathrm{~Hz}^{68}$. Davies et al. fabricated G-PPy supercapacitor which gave a specific capacitance of $237 \mathrm{~F} \mathrm{~g}^{-1}$ for a reasonable deposition time of $120 \mathrm{~s}$. This flexible electrode exhibited energy density of 33 $\mathrm{Wh} \mathrm{kg}^{-1}$ and power density of $1184 \mathrm{~W} \mathrm{~kg}^{-1}$ at scan rate $0.01 \mathrm{~V} \mathrm{~s}^{-1} 69$. Bora et al. synthesized an electrode material using sulfonated graphene and PPy via interfacial polymerization method which exhibited $360 \mathrm{~F} \mathrm{~g}^{-1}$ at a current density of $1 \mathrm{~A} \mathrm{~g} \mathrm{~g}^{-1}{ }^{70}$. NG and its derivatives are another suitable type for designing G-PPy composites. Zu et al. was able to improve rate capability and cycling stability of PPy by adjusting NG content in PPy (cauliflower morphology) homogeneous nanosheet composite. Prepared nanocomposite exhibited a specific capacitance of $255.7 \mathrm{~F} \mathrm{~g}^{-1}$ at current density of $0.2 \mathrm{~A} \mathrm{~g}^{-1}$. Capacitance retention was $93 \%$ of initial value after 1000 cycles implying high stability ${ }^{71}$. Chen et al. developed novel $\mathrm{PPy} /$ polyoxometalate/rGO ternary nanohybrids (TNHs) through a one-pot redox relay approach. The composite showed high areal specific capacitance of $2.61 \mathrm{mF} \mathrm{cm}^{-2}$ as well as good rate stability, excellent flexibility and mechanical stability ${ }^{72}$. Sun et al. synthesized a $\mathrm{PPy} / \mathrm{NG} / \mathrm{MnO}_{2}$ composite via ultrasonic irradiation to obtain a specific capacitance of $258 \mathrm{~F}$ 
$\mathrm{g}^{-1}$ at current density of $1 \mathrm{~A} \mathrm{~g}^{-1}$ 73. Wu et al. synthesized 3D core/ shell GO/ PPy via in-situ surface initialed polymerization method and obtained a specific capacitance value of $370 \mathrm{~F}$ $\mathrm{g}^{-1}$ at a current density of $0.5 \mathrm{~A} \mathrm{~g} \mathrm{~g}^{-1}$. Capacitance retention was $91.2 \%$ of initial value after continuous 4000 cycles ${ }^{74}$. As a conclusive summary, G-PPy composite supercapacitors have given a lot of benefits in the supercapacitor industry, suggesting that they can be further used as a modification of both graphene and PPy.

\section{COMPARISON AND SUMMARY}

Graphene and its derivatives have a great influence on the CPs by improving its morphologies, electrical properties and structural stabilities, thus when they are combined together to create composites, great development of their electrochemical properties can be seen ${ }^{75}$.

Table 02: Specific capacitance of some G-CP composite supercapacitor electrodes.

\begin{tabular}{|c|c|c|c|}
\hline G-CP Composite & Electrolyte & $\begin{array}{c}\text { Specific } \\
\text { Capacita } \\
\text { nce }\left(\text { F g }^{-1}\right)\end{array}$ & Reference \\
\hline Graphene/PANI & $6 \mathrm{M} \mathrm{KOH}$ & 261 & 76 \\
\hline Graphene/CNT/PANI & $\begin{array}{l}1 \mathrm{M} \mathrm{KCl} \text {, 1-ethyl-3-methyl } \\
\text { imidazoliumbis(trifluoromet } \\
\text { hanesulfone)imide (EMI- } \\
\text { TFSI) }\end{array}$ & 271 & 77 \\
\hline Graphene/PANI & $2 \mathrm{M} \mathrm{H}_{2} \mathrm{SO}_{4}$ & 436 & 78 \\
\hline $\mathrm{GO} / \mathrm{MnO}_{2} / \mathrm{PANI}$ & $1 \mathrm{M} \mathrm{Na}_{2} \mathrm{SO}_{4}$ & 512 & 79 \\
\hline Graphene/PANI & $1 \mathrm{M} \mathrm{H}_{2} \mathrm{SO}_{4}$ & 1130 & 80 \\
\hline $\mathrm{rGO} / \mathrm{PANI}$ & $1 \mathrm{M} \mathrm{Na}_{2} \mathrm{SO}_{4}$ & 1337 & 81 \\
\hline GO/PANI & $0.5 \mathrm{M} \mathrm{H}_{2} \mathrm{SO}_{4}$ & 448 & 82 \\
\hline Crumpled graphene/CNT/PANI & $\mathrm{KOH}$ & 456 & 83 \\
\hline $\mathrm{GO} / \mathrm{PANI}$ & $\mathrm{KOH}$ & 1509 & 84 \\
\hline $\mathrm{rGO} / \mathrm{PANI}$ & $1 \mathrm{M} \mathrm{H}_{2} \mathrm{SO}_{4}$ & 1126 & 85 \\
\hline $\begin{array}{l}\text { Sulfonated graphene } \\
\text { (SG)/PANI }\end{array}$ & $1 \mathrm{M} \mathrm{H}_{2} \mathrm{SO}_{4}$ & 931 & 86 \\
\hline $\begin{array}{c}\text { Surfactant-stabilized graphene } \\
\text { (SSG)/PANI }\end{array}$ & $2 \mathrm{M} \mathrm{H}_{2} \mathrm{SO}_{4}$ & 526 & 87 \\
\hline
\end{tabular}




\begin{tabular}{|c|c|c|c|}
\hline rGO/PANI film & $1 \mathrm{M} \mathrm{H}_{2} \mathrm{SO}_{4}$ & 640 & 88 \\
\hline $\begin{array}{l}\text { Graphene nano sheets } \\
\text { (GNS)/CNT/PANI }\end{array}$ & $6 \mathrm{M} \mathrm{KOH}$ & 1035 & 89 \\
\hline GNS/PANI & $6 \mathrm{M} \mathrm{KOH}$ & 1046 & 89 \\
\hline SG/PPy & $1 \mathrm{M} \mathrm{KCl}$ & 285 & 90 \\
\hline rGO/PPy & $3 \mathrm{M} \mathrm{KCl}$ & 224 & 91 \\
\hline $\mathrm{GO} / \mathrm{PPy}$ & $0.1 \mathrm{M} \mathrm{KCl}$ & 356 & 92 \\
\hline GNS/PPy & $1 \mathrm{M} \mathrm{H}_{2} \mathrm{SO}_{4}$ & 482 & 93 \\
\hline GO/PPy & $2 \mathrm{M} \mathrm{H}_{2} \mathrm{SO}_{4}$ & 500 & 94 \\
\hline NG/CNT/PPy & $1 \mathrm{M} \mathrm{KCl}$ & 211 & 95 \\
\hline Graphene/PPy & $1 \mathrm{M} \mathrm{NaNO}_{3}$ & 235 & 96 \\
\hline Graphene/PPy & $1 \mathrm{M} \mathrm{KCl}$ & 310 & 97 \\
\hline $\mathrm{rGO} / \mathrm{PPy}$ & $1 \mathrm{M} \mathrm{KOH}$ & 336 & 98 \\
\hline Graphene/PPy & $1 \mathrm{M} \mathrm{KOH}$ & 418 & 99 \\
\hline Graphene/CNT/PPy & $1 \mathrm{M} \mathrm{H}_{2} \mathrm{SO}_{4}$ & 453 & 100 \\
\hline Graphene/PPy & $1 \mathrm{M} \mathrm{KCl}$ & 466 & 101 \\
\hline Graphene/PPy & $\mathrm{PVA}-\mathrm{H}_{2} \mathrm{SO}_{4}$ & 509 & 102 \\
\hline Graphene/PPy & $0.5 \mathrm{M} \mathrm{H}_{2} \mathrm{SO}_{4}$ & 641 & 103 \\
\hline $\begin{array}{l}\text { Graphene/layered double } \\
\text { hydroxide nanowires/PPy }\end{array}$ & $1 \mathrm{M} \mathrm{KOH}$ & 845 & 104 \\
\hline $\mathrm{rGO} / \mathrm{PPy}$ & $1 \mathrm{M} \mathrm{H}_{2} \mathrm{SO}_{4}$ & 420 & 105 \\
\hline rGO/PPy nanowire & $1 \mathrm{M} \mathrm{KCl}$ & 728 & 106 \\
\hline Exfoliated graphene/ PPy & $3 \mathrm{M} \mathrm{KCl}$ & 351 & 107 \\
\hline Graphene/PPy & $\mathrm{LiClO}_{4}$ & 1510 & 108 \\
\hline
\end{tabular}

\section{CONCLUSION}

In this article, typical recent leading and frontier studies of graphene and CPs (mainly PANI and PPy) based composite materials for supercapacitor electrodes were reviewed. CPs and graphene have many outstanding electrochemical properties as well as other unique features which will enhance the performance of supercapacitor electrodes. Main object of this review is to reveal the difficulties of using pure CPs and graphene alone as the electrode material and to overcome this challenge through a successful approach of developing composite electrode materials using graphene and CPs for the supercapacitor industry. Pure CPs suffer 
problems such as lower energy and power densities and poor cycling stabilities, while graphene and its derivatives have low volumetric capacitances, agglomeration problems, nano-micro transformation effect and incapability of large scale production. In near future scientists will be able to avoid these challenges and to improve the performance by merging the good qualities of graphene and CPs while considering the understandings of storage mechanism, interfacial relation and designs of graphene/CP composites to develop supercapacitors and to ensure the future energy storage requirements.

\section{REFERENCES}

1. Wang, G., Zhang, L., \& Zhang, J., (2012). A review of electrode materials for electrochemical supercapacitors. Chemical Society Reviews. 41, pp.797-828, DOI: https://doi.org/10.1039/c1cs15060j

2. Vangari, M., Pryor, T., \& Jiang, L., (2013). Supercapacitors: Review of materials and fabrication methods. Journal of Energy Engineering. 139, pp.72-79, DOI: https://doi.org/10.1061/(ASCE)EY.1943-7897.0000102

3. Sk, M.M., Yue, C.Y., Ghosh, K., \& Jena, R.K., (2016). Review on advances in porous nanostructured nickel oxides and their composite electrodes for high-performance supercapacitors. Journal of Power Sources. 308, pp.121-140, DOI: https://doi.org/10.1016/j.jpowsour.2016.01.056

4. Lim, E., Jo, C., \& Lee, J., (2016). A mini review of designed mesoporous materials for energy-storage applications: From electric double-layer capacitors to hybrid supercapacitors. Nanoscale. 8, pp.7827-7833, DOI: https://doi.org/10.1039/c6nr00796a

5. Borenstein, A., Hanna, O., Attias, R., Luski, S., Brousse, T., \& Aurbach, D., (2017). Carbonbased composite materials for supercapacitor electrodes: A review. Journal of Materials Chemistry A. 5, pp.12653-12672, DOI: https://doi.org/10.1039/c7ta00863e

6. Kim, B.K., Sy, S., Yu, A., \& Zhang, J., (2015). Electrochemical Supercapacitors for Energy Storage and Conversion. Handbook of Clean Energy Systems. 6, pp.1-25, DOI: https://doi.org/10.1002/9781118991978.hces112

7. Wang, F., Wu, X., Yuan, X., Liu, Z., Zhang, Y., Fu, L., Zhu, Y., Zhou, Q., Wu, Y., \& Huang, W., (2017). Latest advances in supercapacitors: From new electrode materials to novel device designs. Chemical Society Reviews. 46, pp.6816-6854, DOI: https://doi.org/10.1039/c7cs00205j

8. Gao, Y., (2017). Graphene and Polymer Composites for Supercapacitor Applications: a Review. Nanoscale Research Letters, 12, pp.1-17, DOI: https://doi.org/10.1186/s11671-017$\underline{2150-5}$

9. $\quad$ Stankovich, S., Dikin, D.A., Dommett, G.H.B., Kohlhaas, K.M., Zimney, E.J., Stach, E.A., Piner, R.D., Nguyen, S.B.T., \& Ruoff, R.S., (2006). Graphene-based composite materials. Nature. 442, pp.282-286, DOI: https://doi.org/10.1038/nature04969

10. Gómez, H., Ram, M.K., Alvi, F., Villalba, P., Stefanakos, E., \& Kumar, A., (2011). Grapheneconducting polymer nanocomposite as novel electrode for supercapacitors. Journal of Power Sources. 196, pp.4102-4108, DOI: https://doi.org/10.1016/j.jpowsour.2010.11.002

11. Li, X., Cai, W., Colombo, L., \& Ruoff, R.S., (2009). Evolution of graphene growth on Ni and $\mathrm{Cu}$ by carbon isotope labeling. Nano Letters. 9, pp.4268-4272, DOI: 


\section{https://doi.org/10.1021/n1902515k}

12. Wang, Y., Ding, Y., Guo, X., \& Yu, G., (2019). Conductive polymers for stretchable supercapacitors. Nano Research. 12, pp.1978-1987, DOI: https://doi.org/10.1007/s12274019-2296-9

13. Zhang, Y., Sun, X., Pan, L., Li, H., Sun, Z., Sun, C., \& Tay, B.K., (2009). Carbon nanotube$\mathrm{ZnO}$ nanocomposite electrodes for supercapacitors. Solid State Ionics. 180, pp.1525-1528, DOI: https://doi.org/10.1016/j.ssi.2009.10.001

14. Iro, Z.S., Subramani, C., \& Dash, S.S., (2016). A brief review on electrode materials for supercapacitor. International Journal of Electrochemical Science. 11, pp.10628-10643, DOI: https://doi.org/10.20964/2016.12.50

15. Jung, S.H., Myung, Y., Kim, B.N., Kim, I.G., You, I.K., \& Kim, T.Y., (2018). Activated Biomass-derived Graphene-based Carbons for Supercapacitors with High Energy and Power Density. Scientific Reports. 8, pp.1-8, DOI: https://doi.org/10.1038/s41598-018-20096-8

16. Moon, K., Li, Z., Yao, Y., Lin, Z., Liang, Q., Agar, J., Song, M., Liu, M., \& Wong, C.P., (2010). Graphene for ultracapacitors. Proceedings - Electronic Components and Technology Conference. pp.1323-1328, DOI: https://doi.org/10.1109/ECTC.2010.5490644

17. Xia, J., Chen, F., Li, J., \& Tao, N., (2009). Measurement of the quantum capacitance of graphene. Nature Nanotechnology. 4, pp.505-509, DOI: https://doi.org/10.1038/nnano.2009.177

18. Ke, Q., \& Wang, J., (2016). Graphene-based materials for supercapacitor electrodes - A review. Journal of Materiomics. 2, pp.37-54, DOI: https://doi.org/10.1016/j.jmat.2016.01.001

19. Bhuyan, M.S.A., Uddin, M.N., Islam, M.M., Bipasha, F.A., \& Hossain, S.S., (2016). Synthesis of graphene. International Nano Letters. 6, pp.65-83, DOI: https://doi.org/10.1007/s40089-015-0176-1

20. Ramachandran, R., Saranya, M., Velmurugan, V., Raghupathy, B.P.C., Jeong, S.K., \& Grace, A.N., (2015). Effect of reducing agent on graphene synthesis and its influence on charge storage towards supercapacitor applications. Applied Energy. 153, pp.22-31, DOI: https://doi.org/10.1016/j.apenergy.2015.02.091

21. Mitra, S., \& Sampath, S., (2004). Electrochemical capacitors based on exfoliated graphite electrodes. Electrochemical and Solid-State Letters. 7, pp.264-268, DOI: https://doi.org/10.1149/1.1773752

22. Lv, W., Tang, D.M., He, Y.B., You, C.H., Shi, Z.Q., Chen, X.C., Chen, C.M., Hou, P.X., Liu, C., \& Yang, Q.H., (2009). Low-temperature exfoliated graphenes: Vacuum-promoted exfoliation and electrochemical energy storage. ACS Nano. 3, pp.3730-3736, DOI: https://doi.org/10.1021/nn900933u

23. Yan, J., Liu, J., Fan, Z., Wei, T., \& Zhang, L., (2012). High-performance supercapacitor electrodes based on highly corrugated graphene sheets. Carbon. 50, pp.2179-2188, DOI: https://doi.org/10.1016/j.carbon.2012.01.028

24. Arthi G, P.B., \& BD, L., (2015). A Simple Approach to Stepwise Synthesis of Graphene Oxide Nanomaterial. Journal of Nanomedicine \& Nanotechnology. 06, pp.1-4, DOI: https://doi.org/10.4172/2157-7439.1000253

25. Kovtyukhova, N.I., (1999). Layer-by-layer assembly of ultrathin composite films from micron-sized graphite oxide sheets and polycations. Chemistry of Materials. 11, pp.771-778, DOI: https://doi.org/10.1021/cm981085u 
26. Stankovich, S., Piner, R.D., Nguyen, S.B.T., \& Ruoff, R.S., (2006). Synthesis and exfoliation of isocyanate-treated graphene oxide nanoplatelets. Carbon. 44, pp.3342-3347, DOI: https://doi.org/10.1016/j.carbon.2006.06.004

27. Gao, W., Alemany, L.B., Ci, L., \& Ajayan, P.M., (2009). New insights into the structure and reduction of graphite oxide. Nature Chemistry. 1, pp.403-408, DOI: https://doi.org/10.1038/nchem.281

28. Li, Y., Van Zijll, M., Chiang, S., \& Pan, N., (2011). KOH modified graphene nanosheets for supercapacitor electrodes. Journal of Power Sources. 196, pp.6003-6006, DOI: https://doi.org/10.1016/j.jpowsour.2011.02.092

29. Dang, Y.Q., Ren, S.Z., Liu, G., Cai, J., Zhang, Y., \& Qiu, J., (2016). Electrochemical and capacitive properties of carbon dots/reduced graphene oxide supercapacitors. Nanomaterials. 6, pp.1-12, DOI: https://doi.org/10.3390/nano6110212

30. Yang, J., \& Gunasekaran, S., (2013). Electrochemically reduced graphene oxide sheets for use in high performance supercapacitors. Carbon. 51, pp.36-44, DOI: https://doi.org/10.1016/j.carbon.2012.08.003

31. Wang, B., Liu, J., Mirri, F., Pasquali, M., Motta, N., \& Holmes, J.W., (2016). Highperformance graphene-based supercapacitors made by a scalable blade-coating approach. Nanotechnology. 27, pp.165402-165410, DOI: https://doi.org/10.1088/0957$\underline{4484 / 27 / 16 / 165402}$

32. Wu, Z.S., Parvez, K., Feng, X., \& Müllen, K., (2013). Graphene-based in-plane microsupercapacitors with high power and energy densities. Nature Communications. 4, pp.1-8, DOI: https://doi.org/10.1038/ncomms3487

33. Vellacheri, R., Al-Haddad, A., Zhao, H., Wang, W., Wang, C., \& Lei, Y., (2014). High performance supercapacitor for efficient energy storage under extreme environmental temperatures. Nano Energy. 8, pp.231-237, DOI: https://doi.org/10.1016/j.nanoen.2014.06.015

34. Snook, G.A., Kao, P., \& Best, A.S., (2011). Conducting-polymer-based supercapacitor devices and electrodes. Journal of Power Sources. 196, pp.1-12, DOI: https://doi.org/10.1016/j.jpowsour.2010.06.084

35. Zhang, X., Chan-Yu-King, R., Jose, A., \& Manohar, S.K., (2004). Nanofibers of polyaniline synthesized by interfacial polymerization. Synthetic Metals. 145, pp.23-29, DOI: https://doi.org/10.1016/j.synthmet.2004.03.012

36. Chronakis, I.S., Grapenson, S., \& Jakob, A., (2006). Conductive polypyrrole nanofibers via electrospinning: Electrical and morphological properties. Polymer. 47, pp.1597-1603, DOI: https://doi.org/10.1016/j.polymer.2006.01.032

37. Xing, S., Zhao, C., Jing, S., \& Wang, Z., (2006). Morphology and conductivity of polyaniline nanofibers prepared by "seeding" polymerization. Polymer. 47, pp.2305-2313, DOI: https://doi.org/10.1016/j.polymer.2006.02.008

38. Parthasarathy, R. V., \& Martin, C.R., (1994). Template-Synthesized Polyaniline Microtubules. Chemistry of Materials. 6, pp.1627-1632, DOI: https://doi.org/10.1021/cm00046a011

39. Meng, Q., Cai, K., Chen, Y., \& Chen, L., (2017). Research progress on conducting polymer based supercapacitor electrode materials. Nano Energy. 36, pp.268-285, DOI: https://doi.org/10.1016/j.nanoen.2017.04.040 
40. Sivakkumar, S.R., Kim, W.J., Choi, J.A., MacFarlane, D.R., Forsyth, M., \& Kim, D.W., (2007). Electrochemical performance of polyaniline nanofibres and polyaniline/multi-walled carbon nanotube composite as an electrode material for aqueous redox supercapacitors. Journal of Power Sources. 171, pp.1062-1068, DOI: https://doi.org/10.1016/j.jpowsour.2007.05.103

41. Zhu, H., Peng, S., \& Jiang, W., (2013). Electrochemical properties of PANI as single electrode of electrochemical capacitors in acid electrolytes. The Scientific World Journal, 2013, pp.1-8, DOI: https://doi.org/10.1155/2013/940153

42. Yang, Q., Hou, Z., \& Huang, T., (2015). Self-assembled polypyrrole film by interfacial polymerization for supercapacitor applications. Journal of Applied Polymer Science. 132, pp.4-8, DOI: https://doi.org/10.1002/app.41615

43. Shi, Y., Pan, L., Liu, B., Wang, Y., Cui, Y., Bao, Z., \& Yu, G., (2014). Nanostructured conductive polypyrrole hydrogels as high-performance, flexible supercapacitor electrodes. Journal of Materials Chemistry A. 2, pp.6086-6091, DOI: https://doi.org/10.1039/c4ta00484a

44. Hashmi, S.A., Kumar, A., \& Tripathi, S.K., (2005). Investigations on electrochemical supercapacitors using polypyrrole redox electrodes and PMMA based gel electrolytes. European Polymer Journal. 41, pp.1373-1379, DOI: https://doi.org/10.1016/j.eurpolymj.2004.12.013

45. Huang, Y., Tao, J., Meng, W., Zhu, M., Huang, Y., Fu, Y., Gao, Y., \& Zhi, C., (2015). Superhigh rate stretchable polypyrrole-based supercapacitors with excellent cycling stability. Nano Energy. 11, pp.518-525, DOI: https://doi.org/10.1016/j.nanoen.2014.10.031

46. Li, M., \& Yang, L., (2015). Intrinsic flexible polypyrrole film with excellent electrochemical performance. Journal of Materials Science: Materials in Electronics. 26, pp.4875-4879, DOI: https://doi.org/10.1007/s10854-015-2996-1

47. Rajesh, M., Raj, C.J., Kim, B.C., Cho, B.B., Ko, J.M., \& Yu, K.H., (2016). Supercapacitive studies on electropolymerized natural organic phosphate doped polypyrrole thin films. Electrochimica Acta. 220, pp.373-383, DOI: https://doi.org/10.1016/j.electacta.2016.10.118

48. Xu, J., Wang, D., Fan, L., Yuan, Y., Wei, W., Liu, R., Gu, S., \& Xu, W., (2015). Fabric electrodes coated with polypyrrole nanorods for flexible supercapacitor application prepared via a reactive self-degraded template. Organic Electronics. 26, pp.292-299, DOI: https://doi.org/10.1016/j.orgel.2015.07.054

49. Zhang, K., Zhang, L.L., Zhao, X.S., \& Wu, J., (2010). Graphene/polyaniline nanofiber composites as supercapacitor electrodes. Chemistry of Materials. 22, pp.1392-1401, DOI: https://doi.org/10.1021/cm902876u

50. Wang, S., Ma, L., Gan, M., Fu, S., Dai, W., Zhou, T., Sun, X., Wang, H., \& Wang, H., (2015). Free-standing 3D graphene/polyaniline composite film electrodes for high-performance supercapacitors. Journal of Power Sources. 299, pp.347-355, DOI: https://doi.org/10.1016/j.jpowsour.2015.09.018

51. Cong, H.P., Ren, X.C., Wang, P., \& Yu, S.H., (2013). Flexible graphene-polyaniline composite paper for high-performance supercapacitor. Energy and Environmental Science. 6, pp.1185-1191, DOI: https://doi.org/10.1039/c2ee24203f

52. Sun, H., She, P., Xu, K., Shang, Y., Yin, S., \& Liu, Z., (2015). A self-standing nanocomposite foam of polyaniline@reduced graphene oxide for flexible super-capacitors. Synthetic Metals. 209, pp.68-73, DOI: https://doi.org/10.1016/j.synthmet.2015.07.001 
53. Wang, H., Hao, Q., Yang, X., Lu, L., \& Wang, X., (2009). Graphene oxide doped polyaniline for supercapacitors. Electrochemistry Communications. 11, pp.1158-1161, DOI: https://doi.org/10.1016/j.elecom.2009.03.036

54. Gao, S., Zhang, L., Qiao, Y., Dong, P., Shi, J., \& Cao, S., (2016). Electrodeposition of polyaniline on three-dimensional graphene hydrogel as a binder-free supercapacitor electrode with high power and energy densities. RSC Advances. 6, pp.58854-58861, DOI: https://doi.org/10.1039/c6ra06263f

55. Khosrozadeh, A., Darabi, M.A., Xing, M., \& Wang, Q., (2015). Flexible cellulose-based films of polyanilinegraphenesilver nanowire for high-performance supercapacitors. Journal of Nanotechnology in Engineering and Medicine. 6, pp.1-5, DOI: https://doi.org/10.1115/1.4031385

56. Du, Y., Cai, K., \& Shen, S.Z., (2013). Facile preparation and characterization of graphene nanosheet/polyaniline nanofiber thermoelectric composites. Functional Materials Letters. 6, pp.1-6, DOI: https://doi.org/10.1142/S179360471340002X

57. Du, Y., Shen, S.Z., Yang, W., Donelson, R., Cai, K., \& Casey, P.S., (2012). Simultaneous increase in conductivity and Seebeck coefficient in a polyaniline/graphene nanosheets thermoelectric nanocomposite. Synthetic Metals. 161, pp.2688-2692, DOI: https://doi.org/10.1016/j.synthmet.2011.09.044

58. Das, A.K., Karan, S.K., \& Khatua, B.B., (2015). High energy density ternary composite electrode material based on polyaniline (PANI), molybdenum trioxide (MoO3) and graphene nanoplatelets (GNP) prepared by sono-chemical method and their synergistic contributions in superior supercapacitive performance. Electrochimica Acta. 180, pp.1-15, DOI: https://doi.org/10.1016/j.electacta.2015.08.029

59. Dhibar, S., \& Das, C.K., (2015). Electrochemical performances of silver nanoparticles decorated polyaniline/graphene nanocomposite in different electrolytes. Journal of Alloys and Compounds. 653, pp.486-497, DOI: https://doi.org/10.1016/j.jallcom.2015.08.158

60. Shabani Shayeh, J., Ehsani, A., Ganjali, M.R., Norouzi, P., \& Jaleh, B., (2015). Conductive polymer/reduced graphene oxide/Au nano particles as efficient composite materials in electrochemical supercapacitors. Applied Surface Science. 353, pp.594-599, DOI: https://doi.org/10.1016/j.apsusc.2015.06.066

61. Kazemi, S.H., \& Abdollahi Aghdam, S., (2019). High-Performance Asymmetric Supercapacitor Based on Ternary MnO2-Polyaniline-Reduced Graphene Oxide Quantum Dots Nanocomposite Electrode. Journal of Electronic Materials. 48, pp.5088-5098, DOI: https://doi.org/10.1007/s11664-019-07318-z

62. Tayel, M.B., Soliman, M.M., Ebrahim, S., \& Harb, M.E., (2016). Sprayed polyaniline layer onto chemically reduced graphene oxide as electrode for high performance supercapacitor. Synthetic Metals. 217, pp.237-243, DOI: https://doi.org/10.1016/j.synthmet.2016.04.011

63. Liu, M., Wu, X., Chen, C., Wang, Q., Wen, T., \& Wang, X., (2013). Synthesizing the composites of graphene oxide-wrapped polyaniline hollow microspheres for highperformance supercapacitors. Science of Advanced Materials. 5, pp.1686-1693, DOI: https://doi.org/10.1166/sam.2013.1637

64. Kumar, N.A., Choi, H.J., Shin, Y.R., Chang, D.W., Dai, L., \& Baek, J.B., (2012). Polyanilinegrafted reduced graphene oxide for efficient electrochemical supercapacitors. ACS Nano. 6, pp.1715-1723, DOI: https://doi.org/10.1021/nn204688c

65. Biswas, S., \& Drzal, L.T., (2010). Multilayered nanoarchitecture of graphene nanosheets and polypyrrole nanowires for high performance supercapacitor electrodes. Chemistry of 
Materials. 22, pp.5667-5671, DOI: https://doi.org/10.1021/cm101132g

66. Liu, Y., Wang, H., Zhou, J., Bian, L., Zhu, E., Hai, J., Tang, J., \& Tang, W., (2013). Graphene/polypyrrole intercalating nanocomposites as supercapacitors electrode. Electrochimica Acta. 112, pp.44-52, DOI: https://doi.org/10.1016/j.electacta.2013.08.149

67. Xu, C., Sun, J., \& Gao, L., (2011). Synthesis of novel hierarchical graphene/polypyrrole nanosheet composites and their superior electrochemical performance. Journal of Materials Chemistry. 21, pp.11253-11258, DOI: https://doi.org/10.1039/c1jm11275a

68. A. Basnayaka, P., K. Ram, M., Stefanakos, L., \& Kumar, A., (2013). Graphene/Polypyrrole Nanocomposite as Electrochemical Supercapacitor Electrode: Electrochemical Impedance Studies. Graphene. 02, pp.81-87, DOI: https://doi.org/10.4236/graphene.2013.22012

69. Davies, A., Audette, P., Farrow, B., Hassan, F., Chen, Z., Choi, J.Y., \& Yu, A., (2011). Graphene-based flexible supercapacitors: Pulse-electropolymerization of polypyrrole on freestanding graphene films. Journal of Physical Chemistry C. 115, pp.17612-17620, DOI: https://doi.org/10.1021/jp205568v

70. Bora, C., Sharma, J., \& Dolui, S., (2014). Polypyrrole/sulfonated graphene composite as electrode material for supercapacitor. Journal of Physical Chemistry C. 118, pp.2968829694, DOI: https://doi.org/10.1021/jp511095s

71. Zhu, J., Xu, Y., Wang, J., Wang, J., Bai, Y., \& Du, X., (2015). Morphology controllable nanosheet polypyrrole-graphene composites for high-rate supercapacitor. Physical Chemistry Chemical Physics. 17, pp.19885-19894, DOI: https://doi.org/10.1039/c5cp02710a

72. Chen, Y., Han, M., Tang, Y., Bao, J., Li, S., Lan, Y., \& Dai, Z., (2015). Polypyrrolepolyoxometalate/reduced graphene oxide ternary nanohybrids for flexible, all-solid-state supercapacitors. Chemical Communications. 51, pp.12377-12380, DOI: https://oi.org/10.1039/c5cc02717a

73. Sun, W., Chen, L., Wang, Y., Zhou, Y., Meng, S., Li, H., \& Luo, Y., (2016). Synthesis of Highly Conductive PPy/Graphene/MnO 2 Composite Using Ultrasonic Irradiation. Synthesis and Reactivity in Inorganic, Metal-Organic and Nano-Metal Chemistry. 46, pp.437-444, DOI: https://doi.org/10.1080/15533174.2014.988250

74. Wu, W., Yang, L., Chen, S., Shao, Y., Jing, L., Zhao, G., \& Wei, H., (2015). Core-shell nanospherical polypyrrole/graphene oxide composites for high performance supercapacitors. RSC Advances. 5, pp.91645-91653, DOI: https://doi.org/10.1039/c5ra17036b

75. Kandasamy, S.K., \& Kandasamy, K., (2018). Recent Advances in Electrochemical Performances of Graphene Composite (Graphene-Polyaniline/Polypyrrole/Activated Carbon/Carbon Nanotube) Electrode Materials for Supercapacitor: A Review. Journal of Inorganic and Organometallic Polymers and Materials. 28, pp.559-584, DOI: https://doi.org/10.1007/s10904-018-0779-x

76. Li, X., Song, H., Zhang, Y., Wang, H., Du, K., Li, H., Yuan, Y., \& Huang, J., (2012). Enhanced electrochemical capacitance of graphene nanosheets coating with polyaniline for supercapacitors. International Journal of Electrochemical Science. 7, pp.5163-5171

77. Cheng, Q., Tang, J., Shinya, N., \& Qin, L.C., (2013). Polyaniline modified graphene and carbon nanotube composite electrode for asymmetric supercapacitors of high energy density. Journal of Power Sources. 241, pp.423-428, DOI: https://doi.org/10.1016/j.jpowsour.2013.04.105

78. Rajagopalan, B., Hur, S.H., \& Chung, J.S., (2015). Surfactant-treated graphene covered polyaniline nanowires for supercapacitor electrode. Nanoscale Research Letters. 10, pp.1-9, 


\section{DOI: https://doi.org/10.1186/s11671-015-0888-1}

79. Han, G., Liu, Y., Zhang, L., Kan, E., Zhang, S., Tang, J., \& Tang, W., (2014). MnO2 nanorods intercalating graphene oxide/polyaniline ternary composites for robust high-performance supercapacitors. Scientific Reports. 4, pp.1-7, DOI: https://doi.org/10.1038/srep04824

80. Li, J., Xie, H., Li, Y., Liu, J., \& Li, Z., (2011). Electrochemical properties of graphene nanosheets/polyaniline nanofibers composites as electrode for supercapacitors. Journal of Power Sources. 196, pp.10775-10781, DOI: https://doi.org/10.1016/j.jpowsour.2011.08.105

81. Nguyen, V.H., Lamiel, C., Kharismadewi, D., Tran, V.C., \& Shim, J.J., (2015). Covalently bonded reduced graphene oxide/polyaniline composite for electrochemical sensors and capacitors. Journal of Electroanalytical Chemistry. 758, pp.148-155, DOI: https://doi.org/10.1016/j.jelechem.2015.10.023

82. Hassan, M., Reddy, K.R., Haque, E., Faisal, S.N., Ghasemi, S., Minett, A.I., \& Gomes, V.G., (2014). Hierarchical assembly of graphene/polyaniline nanostructures to synthesize freestanding supercapacitor electrode. Composites Science and Technology. 98, pp.1-8, DOI: https://doi.org/10.1016/j.compscitech.2014.04.007

83. Jo, E.H., Jang, H.D., Chang, H., Kim, S.K., Choi, J.H., \& Lee, C.M., (2017). 3 D NetworkStructured Crumpled Graphene/Carbon Nanotube/Polyaniline Composites for Supercapacitors. ChemSusChem. 10, pp.2210-2217, DOI: https://doi.org/10.1002/cssc.201700212

84. Tayel, M.B., Soliman, M.M., Ebrahim, S., \& Harb, M.E., (2016). An Introduced Hybrid Graphene/Polyaniline Composites for Improvement of Supercapacitor. Journal of Electronic Materials. 45, pp.820-828, DOI: https://doi.org/10.1007/s11664-015-4212-8

85. Wang, H., Hao, Q., Yang, X., Lu, L., \& Wang, X., (2010). A nanostructured graphene/polyaniline hybrid material for supercapacitors. Nanoscale. 2, pp.2164-2170, DOI: https://doi.org/10.1039/c0nr00224k

86. Hao, Q., Wang, H., Yang, X., Lu, L., \& Wang, X., (2011). Morphology-Controlled Fabrication of Sulfonated Graphene/Polyaniline Nanocomposites by Liquid/Liquid Interfacial Polymerization and Investigation of their Electrochemical Properties. Nano Research. 4, pp.323-333, DOI: https://doi.org/10.1007/s12274-010-0087-4

87. Mao, L., Zhang, K., On Chan, H.S., \& Wu, J., (2012). Surfactant-stabilized graphene/polyaniline nanofiber composites for high performance supercapacitor electrode. Journal of Materials Chemistry. 22, pp.80-85, DOI: https://doi.org/10.1039/c1jm12869h

88. Feng, X.M., Li, R.M., Ma, Y.W., Chen, R.F., Shi, N.E., Fan, Q.L., \& Huang, W., (2011). One-step electrochemical synthesis of graphene/polyaniline composite film and its applications. Advanced Functional Materials. 21, pp.2989-2996, DOI: https://doi.org/10.1002/adfm.201100038

89. Yan, J., Wei, T., Fan, Z., Qian, W., Zhang, M., Shen, X., \& Wei, F., (2010). Preparation of graphene nanosheet/carbon nanotube/polyaniline composite as electrode material for supercapacitors. Journal of Power Sources. 195, pp.3041-3045, DOI: https://doi.org/10.1016/j.jpowsour.2009.11.028

90. Liu, A., Li, C., Bai, H., \& Shi, G., (2010). Electrochemical deposition of polypyrrole/sulfonated graphene composite films. Journal of Physical Chemistry C. 114, pp.22783-22789, DOI: https://doi.org/10.1021/jp108826e

91. Wang, J., Xu, Y., Zhu, J., \& Ren, P., (2012). Electrochemical in situ polymerization of reduced graphene oxide/polypyrrole composite with high power density. Journal of Power 
Sources. 208, pp.138-143, DOI: https://doi.org/10.1016/j.jpowsour.2012.02.018

92. Zhu, C., Zhai, J., Wen, D., \& Dong, S., (2012). Graphene oxide/polypyrrole nanocomposites: One-step electrochemical doping, coating and synergistic effect for energy storage. Journal of Materials Chemistry. 22, pp.6300-6306, DOI: https://doi.org/10.1039/c2jm16699b

93. Zhang, D., Zhang, X., Chen, Y., Yu, P., Wang, C., \& Ma, Y., (2011). Enhanced capacitance and rate capability of graphene/polypyrrole composite as electrode material for supercapacitors. Journal of Power Sources. 196, pp.5990-5996, DOI: https://doi.org/10.1016/j.jpowsour.2011.02.090

94. Zhang, L.L., Zhao, S., Tian, X.N., \& Zhao, X.S., (2010). Layered graphene oxide nanostructures with sandwiched conducting polymers as supercapacitor electrodes. Langmuir. 26, pp.17624-17628, DOI: https://doi.org/10.1021/la103413s

95. Lu, X., Dou, H., Yuan, C., Yang, S., Hao, L., Zhang, F., Shen, L., Zhang, L., \& Zhang, X., (2012). Polypyrrole/carbon nanotube nanocomposite enhanced the electrochemical capacitance of flexible graphene film for supercapacitors. Journal of Power Sources. 197, pp.319-324, DOI: https://doi.org/10.1016/j.jpowsour.2011.08.112

96. Ma, L., Liu, R., Niu, H., Zhao, M., \& Huang, Y., (2016). Flexible and freestanding electrode based on polypyrrole/graphene/bacterial cellulose paper for supercapacitor. Composites Science Technology. 137, pp.87-93, DOI: https://doi.org/10.1016/j.compscitech.2016.10.027

97. Zuo, X., Zhang, Y., Si, L., Zhou, B., Zhao, B., Zhu, L., \& Jiang, X., (2016). One-step electrochemical preparation of sulfonated graphene/polypyrrole composite and its application to supercapacitor. Journal of Alloys and Compounds. 688, pp.140-148, DOI: https://doi.org/10.1016/j.jallcom.2016.07.184

98. Xu, J., Wang, D., Yuan, Y., Wei, W., Duan, L., Wang, L., Bao, H., \& Xu, W., (2015). Polypyrrole/reduced graphene oxide coated fabric electrodes for supercapacitor application. Organic Electronics. 24, pp.153-159, DOI: https://doi.org/10.1016/j.orgel.2015.05.037

99. He, Y., Bai, Y., Yang, X., Zhang, J., Kang, L., Xu, H., Shi, F., Lei, Z., \& Liu, Z.H., (2016). Holey graphene/polypyrrole nanoparticle hybrid aerogels with three-dimensional hierarchical porous structure for high performance supercapacitor. Journal of Power Sources. 317, pp.1018, DOI: https://doi.org/10.1016/j.jpowsour.2016.03.089

100. Aphale, A., Maisuria, K., Mahapatra, M.K., Santiago, A., Singh, P., \& Patra, P., (2015). Hybrid electrodes by in-situ integration of graphene and carbon-nanotubes in polypyrrole for supercapacitors. Scientific Reports. 5, pp.1-8, DOI: https://doi.org/10.1038/srep14445

101. Sahoo, S., Dhibar, S., Hatui, G., Bhattacharya, P., \& Das, C.K., (2013). Graphene/polypyrrole nanofiber nanocomposite as electrode material for electrochemical supercapacitor. Polymer. 54, pp.1033-1042, DOI: https://doi.org/10.1016/j.polymer.2012.12.042

102. Kashani, H., Chen, L., Ito, Y., Han, J., Hirata, A., \& Chen, M., (2016). Bicontinuous nanotubular graphene-polypyrrole hybrid for high performance flexible supercapacitors. Nano Energy. 19, pp.391-400, DOI: https://doi.org/10.1016/j.nanoen.2015.11.029

103. Pattananuwat, P., \& Aht-ong, D., (2017). Controllable morphology of polypyrrole wrapped graphene hydrogel framework composites via cyclic voltammetry with aiding of poly (sodium 4-styrene sulfonate) for the flexible supercapacitor electrode. Electrochimica Acta. 224, pp.149-160, DOI: https://doi.org/10.1016/j.electacta.2016.12.036

104. Li, X., Zhang, Y., Xing, W., Li, L., Xue, Q., \& Yan, Z., (2016). Sandwich-like graphene/polypyrrole/layered double hydroxide nanowires for high-performance 
supercapacitors. Journal of Power Sources. 331, pp.67-75, DOI: https://doi.org/10.1016/j.jpowsour.2016.09.034

105. Liu, Y., Zhang, Y., Ma, G., Wang, Z., Liu, K., \& Liu, H., (2013). Ethylene glycol reduced graphene oxide/polypyrrole composite for supercapacitor. Electrochimica Acta. 88, pp.519525, DOI: https://doi.org/10.1016/j.electacta.2012.10.082

106. Li, J., Xie, H., \& Li, Y., (2013). Fabrication of graphene oxide/polypyrrole nanowire composite for high performance supercapacitor electrodes. Journal of Power Sources. 241, pp.388-395, DOI: https://doi.org/10.1016/j.jpowsour.2013.04.144

107. Song, Y., Xu, J.L., \& Liu, X.X., (2014). Electrochemical anchoring of dual doping polypyrrole on graphene sheets partially exfoliated from graphite foil for high-performance supercapacitor electrode. Journal of Power Sources. 249, pp.48-58, DOI: https://doi.org/10.1016/j.jpowsour.2013.10.102

108. Mini, P.A., Balakrishnan, A., Nair, S. V., \& Subramanian, K.R.V., (2011). Highly super capacitive electrodes made of graphene/poly(pyrrole). Chemical Communications. 47, pp.5753-5755, DOI: https://doi.org/10.1039/c1cc00119a 